\title{
Analysis of the Current Situation and Improvement Strategies of College English Informatization Teaching Based on MOOC Platform
}

\author{
Zhao Mei \\ Shandong Institute of Commerce and Technology,Jinan, Shandong,250014
}

\begin{abstract}
The advent of the information age has brought new changes to all walks of life, and also established a new platform for autonomous learning for the majority of learners. In the context of the information age, college English teaching is also undergoing reforms in response to changes, and is constantly moving towards information and technology development. Combining the rise and promotion of the new "Mu-class" teaching methods and methods in the Internet era, it also provides a new path for college English information-based teaching. This article starts discussion and research on this.
\end{abstract}

Keywords: $M O O C$, College English, informatization, teaching status, improvement strategies, analysis

\section{Introduction}

With the advent of the 21 st century informatization era, the era of informatization teaching has arrived. Informatization teaching, while setting up an independent learning platform for learners, also provides a new type of teaching path for learners [1]. Language as a tool requires long and slow immersion, but also requires learners to learn autonomously. It is difficult to improve the efficiency if they are forcibly instilled in learners. Major universities in China are actively investing in the construction of new teaching models and learning platforms. This is not only a full use of resources, but also a new improvement method to resolve insufficient teaching. Among them, MOOC is a new teaching mode and learning platform, which also has a positive effect on college English teaching.

\section{MOOC Basic Concepts}

MOOC is the abbreviation of Massive Open Online Course. The Chinese translation of it is "large-scale online open course". After it emerged in the United States in 2008, it was quickly and widely used. Among them, "M" stands for Massivve (large scale), the second "O" stands for Open, the third "O" stands for Online, and "C" stands for Course, which is generally Network-based large-scale network open course [2].

Since 2012, MOOC has entered China, and a variety of online teaching modes have begun. With the development of information technology, the research on MOC's theoretical construction and operating mechanism has become increasingly mature, which also marks the comprehensive arrival of MOOC. MOOC is a very good platform with a high degree of structure. Each course has a clear start time and end time. The content of most MOOC courses is mainly video lectures. The length of the video is about 5 to 15 minutes. A variety of media is used to present and explain the course content through case combinations. In addition to online communication, a new online and offline learning platform construction.

\section{Problems in College English Teaching under the Mood Mode}

\subsection{Problem of Insufficient Supervision System}

In the online teaching mode, the interaction between teachers and students is carried out through a network platform. The shortcomings of face-to-face communication make teachers unable to truly understand the actual learning status of students. There are also situations in which students conceal learning progress, find someone to take classes, answer questions, and complete homework. It is necessary to set up a corresponding supervision system.

\subsection{Problems with Limited Teaching Resources}

With the increasing recognition of the MOOC teaching model, people's expectations for MOOC English teaching have gradually increased. Students hope that the English teaching under this model can expand the teaching content, not just limited to textbooks. For example, working with overseas students the learning requirements make the English level really improve.

\subsection{Problems with Incomplete Curriculum}

The curriculum, which mainly focuses on listening, 
speaking, reading, writing, and comprehensive English, cannot meet the needs of all students. Large class teaching is not targeted, students can not keep up with the teacher's lecture progress, students' practical ability to use English is difficult to improve, and can not meet the needs of the enterprise when looking for a job.

\subsection{Fairness of the Evaluation System}

Taking final grades and ordinary grades as the evaluation criteria can not objectively reflect the students 'English level and can not effectively reflect the students' true level. The proportion of MOOC grades in total grades is a question worth discussing.

\section{STRATEGIESFOR IMPROVING COLLEGE ENGLISH INFORMATIZATION TEACHING BASED ON MOOC}

\section{PLATFORM}

\subsection{Restructuring the Curriculum Model}

It is necessary to organically integrate the teaching of MOOC with traditional teaching, reconstruct the teaching mode of English course, and maximize the efficiency of MOOC teaching. The restructured curriculum model serves as a supplement to MOOC English teaching as a traditional classroom teaching. It makes full use of MOOC teaching resources to enrich the content of classroom teaching. Teachers monitor the student's completion in real time through the network to ensure that students complete homework on time. Linking theory with practice, constructing efficient classrooms, improving classroom teaching efficiency, and forming open lessons can provide students with more convenient and flexible learning opportunities and learning resources, that is, as long as they are connected to the Internet, students will get the latest English learning materials. This requires teachers to integrate theory with practice as much as possible in the classroom, focusing on both knowledge and practicality, in order to meet the needs of students for the purpose of knowledge, to cultivate students' learning ability and language expression skills. Teachers should follow the principle of systematization in the teaching process. According to the systematic nature of the curriculum chapters and lessons, pay attention to the relationship between knowledge, especially the vocabulary with similar meanings. Make sure that the narrative logic is clear. Life experiences are connected, and with the help of the MOOC platform, a relaxed and harmonious classroom atmosphere is created.

\subsection{Hand over the Lesson}

Through online teaching, students can independently choose the content and topics of interest to learn. This interest-based learning can fully stimulate students' enthusiasm for English, improve their classroom activity, and effectively complete homework assigned by teachers, thereby improving efficiency and level of English learning. Teachers carry out small-scale experiments first when they fully develop MOOCs. After fully understanding MOOCs, they determine the scope of MOOCs and effectively improve students' listening, speaking, and reading skills. In practical applications, teachers also need to choose the appropriate MOOC system and type according to the English level of different majors, and organize teaching strategies according to the actual situation of the overall English level of students. Use the type of advocacy lessons to teach students based on their aptitude, so that students are no longer passive recipients but active participants. They assist in various learning punches and analyze personal learning data in order to see changes in their English ability and stimulate students' passion for English learning. Therefore, we use the rich types of MOOCs to improve students' autonomous learning ability.

\subsection{Further Improve the Course Evaluation System}

We are supposed to establish a suitable evaluation system so that a certain percentage of the students' final grades will achieve in MOOC. In this way, students are encouraged to participate in MOOC courses. Teachers and students must participate in MOOC classes to discuss the learning content of English. Teachers and students must also evaluate each other's performance.

\section{CONCLUSION}

All in all, as a new learning platform and teaching method, MOOC is a general trend to enter university classrooms. Combining it with traditional classrooms to build a mixed teaching model is also the only way for the development of the times. MOOC not only injects fresh blood into traditional classroom teaching, but also gives play to its superiority and provides new ideas for college English classroom reform [6]. Based on the MOOC platform, college English teachers need to be more proficient in mastering network and video production technologies, detailed teaching modules and course types. It is recognized that MOOC platform can only be used as a supplement to classroom teaching. Students master the level of knowledge and skills, and carry out developmental evaluations to promote their all-round development.

\section{REFERENCES}

[1] Mao Haixia, Liu Fei, Wu Qian. Research on the Status Quo and Strategies of Listening Autonomous Learning of English Majors in Multimedia Environment_-Taking Hunan University of Science and Technology as an Example [J] .Modern Communication, 2019 (6): 38-38. 
[2] Xiao Mengjie. Application of FiF Oral Training System in College English Oral Teaching under the Background of Mobile Learning [J]. Campus English, 2019 (14): 50-51.

[3] Li Zijie, Zhu Jianbing. Prompt exploration of college English information-based teaching reforms - concurrently discussing the shortcomings and countermeasures of college English multimedia autonomous learning platforms [J]. Bilingual Studies, 2019 (06M): 139-140.

[4] Yuan Xiaowei. College English Informatization Teaching Status and Reform Suggestions in the Network Age [J]. Journal of Jiamusi Vocational College, 2018 (7): 408-409.

[5] Ji Xiaoli, Wang Yan, Fang Xiaoyong, Gong Jian. The Status Quo and Development Strategies of College English Teachers' Informatization Teaching Ability: Based on a Survey of 76 Universities in Jiangsu Province [J]. China Education Informatization, 2018 (24): 72- 76.

[6] Wang Chunhui. Design and Practice of College English Audiovisual Teaching Strategy Based on Network Platform [J] .Modern Communication, 2018 (5): 175-176. 